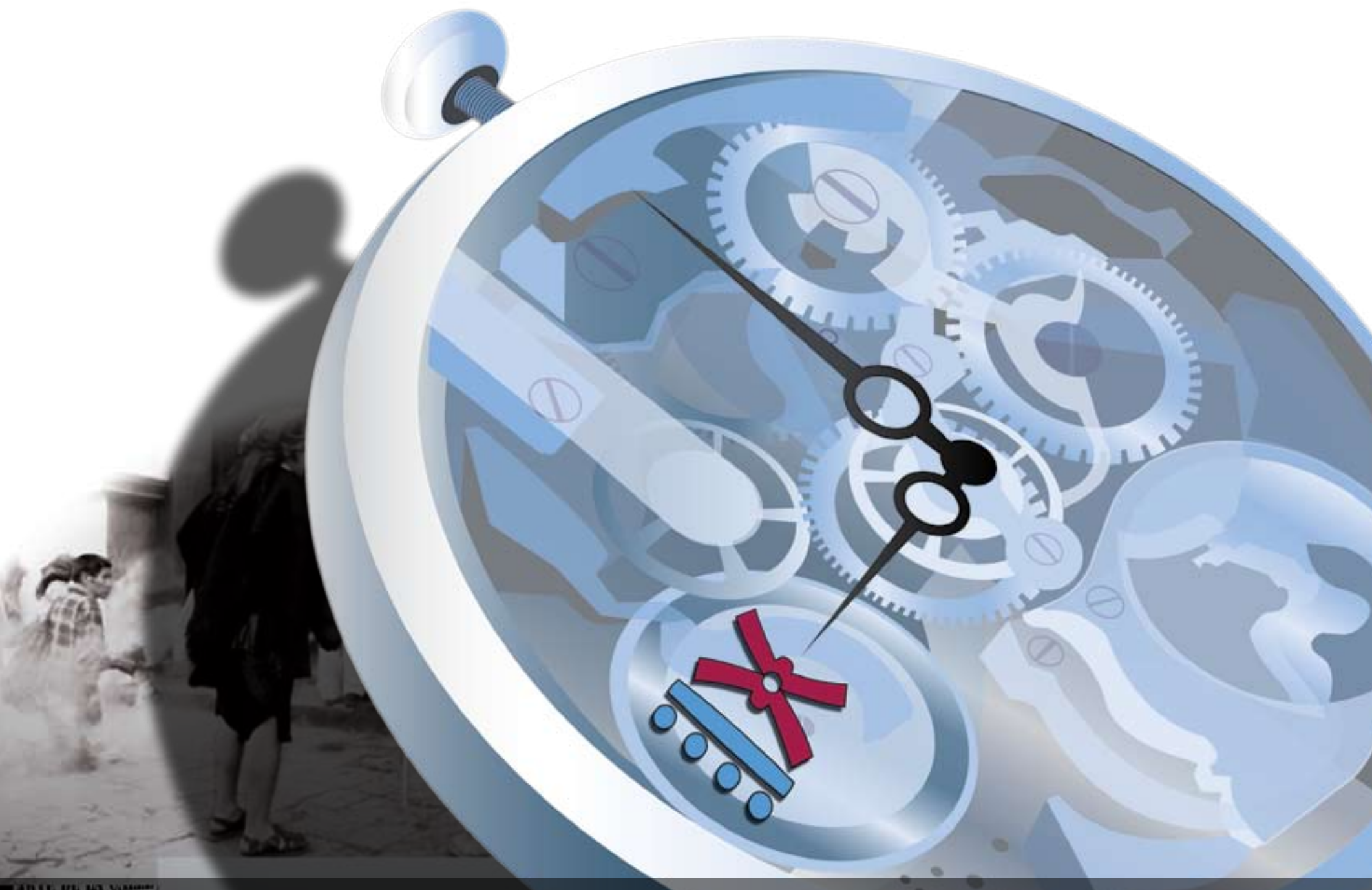

$9^{\circ}$ C O N G RESO 2. CENTROAMERICANO DE H ISTO R I A

Universidad de Costa Rica

ISSN 1409-469X

Fecha de recepción: 15 de mayo 2008 Fecha de aceptación: 30 de mayo 2008

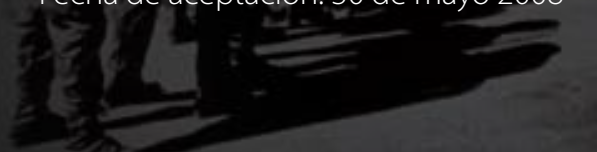

El trabajo de rescate de la de la memoria histórica del Pueblo Indígena de Jinotega (Nicaragua) como un aporte a los procesos de interculturalidad.

Miembros del Consejo Editorial:

Dr. Ronny Viales, Dr. Juan José Marín

Editores Técnicos:

Allan Fonseca, Andrés Cruz, Gabriela Soto
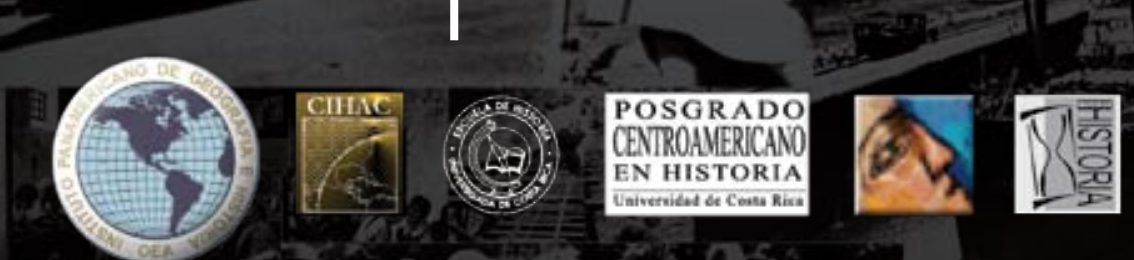


\section{El trabajo de rescate de la de la memoria histórica del Pueblo Indígena de Jinotega (Nicaragua) como un aporte a los procesos de interculturalidad. Eje temático: Cultura, resistencia y
memoria}

Dr. Luis A. Lobato Blanco

Institución de procedencia: Universidad Nacional Autónoma de Nicaragua (UNAN-Managua), Facultad de Humanidades y Ciencias Jurídicas

Titulación académica: Doctor en Historia; Cargo: Director del Departamento de Historia

Dirección de la oficina: Recinto Universitario "Rubén Darío”, UNAN-Managua, Departamento de Historia, Pabellón 18, Managua, Nicaragua.

Telefax: 2786769 Ext. 173; celular: 8821366

Correo electrónico: alobato@unan.edu.ni, alfredolobato@yahoo.es 


\section{$\underline{\text { RESUMEN }}$}

La comunidad indígena de Jinotega abarca un total de 43.889 manzanas de extensión divididas en dos lotes: 36,000 en el lote número 1 y 7,000 en el lote número 2. La población indígena agrupa alrededor de 40,000 personas que habitan principalmente en dos municipios, el de Jinotega, y el de Santa María de Pantasma, en el mismo departamento, donde hay una cifra estimada entre 4,000 y 5,000 indígenas constituyendo en ambos casos vestigios de lo que en la etapa prehispánica constituyó el señorío Chorotega.

La ponencia que se propone es, en parte, el fruto de las actividades de capacitación realizadas por un colectivo docente de la UNAN-Managua que benefician a las comunidades integradas en el pueblo indígena de Jinotega. En la misma, se incluye una semblanza de la investigación de su comunidad por parte de los asistentes a los cursos realizados. Los testimonios de los miembros del pueblo indígena basados en el trabajo concienzudo en cada una de las comarcas son complementadas con el trabajo de reconstrucción histórica de cada una de las comunidades. El objetivo central de la ponencia es demostrar cómo a partir del fortalecimiento de la identidad y de la capacidad del liderazgo indígena, así como de la elevación de la autoestima, es posible rescatar la memoria colectiva.

Para la realización del trabajo de investigación se optó por una metodología de trabajo reflexión-acción-participación. Cabe señalar que el trabajo que se presenta parte de las aportaciones de historiadores como Jeffrey Gould, que han tratado con gran acierto recuperar la memoria histórica del indígena nicaragüense. 


\section{INTRODUCCIÓN}

La presente ponencia es el fruto de las actividades de investigación capacitación que benefician y seguirán beneficiando a las comunidades integradas en el pueblo indígena de Jinotega. Este plan se llevó a cabo en el período comprendido entre el 22 de mayo y el 19 de agosto del año 2006 y fue desarrollado por el Departamento de Historia de la UNAN-Managua con el importante auspicio de la Agencia Asturiana de Cooperación al Desarrollo quien como organización dedicada al desarrollo de los pueblos más desfavorecidos apoyó integralmente el proyecto ejecutado por nuestra universidad bajo el título Programa de Investigación en historia Regional y Local. Apoyo al sector educativo en Nicaragua.

Estas páginas están destinadas, además, a perpetuar el testimonio de los participantes en el programa de fortalecimiento de líderes locales por medio de la narración de las historias de sus respectivas comunidades.

En esta ponencia se incluye una semblanza de la investigación de su comunidad por parte de los asistentes a los cursos realizados. Tales testimonios basados en el trabajo concienzudo en cada una de las comarcas son complementadas con la visión de los docentes que constituyeron una pilar básico para que el programa tuviera el éxito requerido.

Finalmente, debemos expresar que esta hermosa tarea de enriquecer al liderazgo comunitario no hubiera sido posible sin la aportación solidaria del pueblo y 


\section{OI $9^{\circ}$ CONGRESO \\ C CENTROAMERICANO \\ UI DE HISTORIA \\ Universidad de costa Rice}

Indexaciones: Repositorio de Revistas UCR, DIALNET, Latindex, REDALYC Directorio y recolector de recursos digitales del Ministerio de Cultura de España, Directory of Open Access Journals. Diálogos Revista Electrónica de Historia ISSN 1409-469X. Número especial 2008. Dirección web: http://historia.fcs.ucr.ac.cr/dialogos.htm

gobierno de Asturias (España) ni sin el firme apoyo de las autoridades de la UNAN-

Managua. 


\section{Estado de la cuestión}

Los estudios de Historia Regional y Local y la manera en que deben abordarse tienen su precedente universal en la escuela historiográfica francesa de finales del siglo XIX y principios del siglo XX, movimiento que llevó a la fundación de la Escuela de los Anales en 1929, bajo la guía de Marc Bloch y Lucien Febvre. Esta corriente que se convirtió en una de las principales del pasado siglo y que mantiene toda su vigencia, propugnó dos cuestiones básicas de sumo interés para los historiadores, en particular para los que nos dedicamos a los estudios de historia regional y local.

La primera fue la de enfocar la historia como problema, alejándola del positivismo reproductivo. La otra fue la consideración acerca del concepto de espacio, con la delimitación de regiones y localidades a partir del espacio geográfico, a tono con las proyecciones de la Geografía Moderna, enfoque a partir del cual el hombre se comprende como centro de la dinámica regional y por tanto del estudio de la región.

El espacio se entiende como el elemento activo dentro de las relaciones hombre-medio. En este aspecto se destacan las aportaciones que realizaron, después de finalizada la Segunda Guerra Mundial, los historiadores Fernand Braudel y Pierre Vilar, respecto al análisis de la historia como totalidad y las cuestiones de periodización y conceptualización, que representaron un salto de calidad en los análisis de las ciencias humanísticas contemporáneas.

Esta tendencia historiográfica penetró primeramente en Europa y Estados Unidos. Posteriormente, en la década de 1960, llegó a América Latina, donde se produjo un empuje vertiginoso de este 
tipo de investigaciones. El objetivo fundamental de la misma es que se conozca y reconozca el pasado legítimo de las regiones y localidades que es injustamente olvidado en las historias nacionales, las que muchas veces ofrecen generalizaciones equivocadas en la medida que no reflejan el desarrollo de los espacios regionales con su particularidades y diferencias.

Durante mucho tiempo se han subvalorado los estudios regionales y locales; mucho más el tratamiento de aquellos espacios que han tenido una evolución marginada de los cambios y tendencias nacionales. Tal realidad del mundo científico no está divorciada de la práctica y complejidades de las formaciones nacionales latinoamericanas.

En América Latina, el interés por esas problemáticas aludido al inicio, devino en producciones de organizaciones académicas y organismos internacionales como la Comisión Económica Para América Latina (CEPAL). En la mayoría de ellos ha predominado el mismo enfoque geoeconómico. Más recientemente, sobresalen los resultados de la Dra. Susana Bandieri acerca de la región patagónica sur de Argentina, cuyo análisis más detenido se dirige a las redes mercantiles y las formaciones culturales de esa región con Chile. Más recientemente la historiadora cubana Ivette García ha hecho importantes aportaciones partiendo del análisis de la realidad de la región de Baracoa en el oriente de la isla. Otros historiadores latinoamericanos han abordado la apasionante realidad de las localidades y regiones siguiendo la senda del importante trabajo de Luis González y González

En una proyección más amplia, acometer el estudio de regiones históricas marginadas debe constituir, en América Latina, una preocupación para el medio académico y político. En la 
complejidad de nuestro tiempo, ellas son más vulnerables que las grandes urbes y regiones de mediano nivel de desarrollo, a las atrofias que provocan las coyunturas de crisis económicas y hegemonías a escala mundial y hemisférica. Sin embargo, la emergencia práctica y científica de los procesos globales, presenta el peligro de que se relegue la importancia de ellas, o que se arrinconen en el mero recreo de la memoria histórica.

Para conocer el trayecto de una región histórica es preciso descubrir el sustento de los vínculos, la homogeneidad y la coherencia que la región contiene. Esa es la labor del historiador regional. El carácter objetivo lo determina la existencia material, y el subjetivo el sentido de su uso como instrumento de trabajo para el investigador, en cuyo caso resulta válida la clasificación que utilizan algunos historiadores, definiéndola como región formal o funcional. Formal cuando el énfasis se pone en la homogeneidad de un elemento. Funcional, cuando este se hace en el sistema de relaciones funcionales dentro de un sistema territorial integrado.

Partiendo de la lectura de diversas experiencias de este tipo de investigaciones, es importante que no aferrarnos a esquemas rígidos de interpretación de la realidad histórica, sino enfrentar el objeto de investigación, desde una concepción de la historia como totalidad, estudiando el proceso tal como el hombre, que es su centro, lo vive, en una multiplicidad de relaciones físicas, económicas, mercantiles, políticas, sociales y culturales en su más amplia acepción.

El reto ha sido entonces situar a Nicaragua a la altura del desarrollo de la ciencia histórica en el 
mundo y en correspondencia con la tendencia latinoamericana de llevar a la práctica los estudios de historia regional y local para llegar a criterios científicos que permitan conformar la historia nacional.

Los estudios regionales alcanzan en los últimos tiempos una importancia relevante, entre otras razones como base de superación del enfoque la historia nacional tomando como patrón las capitales. El actual empeño tiene como propósito revelar las riquezas de las localidades y regiones cubanas y el lugar que desempeñan éstas en el proceso de formación de nuestra nacionalidad.

En el caso de Nicaragua pocos son los estudios que se han dedicado a analizar la región histórica. Posiblemente el estudio más consistente desde el punto de vista socio-económico sea el desarrollado por Dora María Téllez dedicado a abordar el proceso de privatización de la tierra en Matagalpa y Jinotega en el siglo XIX por parte de los regimenes libero-conservadores, lo que condujo al despojo de las propiedades en manos principalmente de las comunidades indígenas ${ }^{1}$.

Aunque anterior en el tiempo, este estudio se complementaría con el soberbio trabajo del profesor Jeffrey Gould, destinado a combatir el mito de los tres supuestos del orden establecido: una Nicaragua mestiza, católica y de habla hispana ${ }^{2}$. Frente a esta realidad se demuestra en esa obra la existencia de comunidades indígenas organizadas y que pagaron con su vida la osadía de oponerse al orden establecido. Pero la obra de Gould demuestra, además, la existencia de

1 Téllez, Dora María. Muera la gobierna. Colonización en Matagalpa y Jinotega (18201890). Managua, Ed. URACCAN, 1999.

2 Gould, Jeffrey. El mito de la Nicaragua mestiza y la resistencia indígena, 1880-1980. San José, Editorial de la Universidad de Costa Rica, 1997. 
una realidad no mestiza más allá de los núcleos conocidos de Monimbó, Sutiaba y la Costa Atlántica.

En la misma tónica, el Departamento de Historia de la UNAN-Managua ha incursionado desde hace seis años en el estudio pormenorizado de las distintas regiones del país, pero completándolo con el apoyo a la comunidad indígena de Jinotega en la configuración de las historias comunitarias y de los proyectos de desarrollo definidos por ellos mismos.

No obstante, pretendemos reflejar, a través de la presente ponencia, lo que constituye la gran tarea de reflejar no solo la historia de las localidades y regiones, sino el acompañamiento reflexivo y práctico de comunidades indígenas que luchan por evitar la desaparición cultural y física. Tal cuestión ha sido para los nuevos científicos sociales un elemento de aprendizaje y de aprehensión de nuevas realidades hasta entonces no estudiadas.

Metodología y Fuentes

La Metodología de trabajo estuvo centrada en el eje capacitación-acción reflexión

Los métodos utilizados fueron los siguientes:

- El método analítico sintético a partir de los materiales suministrados por los propios líderes. En este sentido fue notorio el bagaje de fuentes escritas y orales presentadas por los participantes en los talleres de capacitación.

- El método de observación, pues se llevaron a cabo visitas a las propias comunidades donde se comprobó el estado de la organización comunitaria. 
Representó una evidencia significativa comprobar los importantes niveles de organización y el desarrollo del liderazgo indígena.

- El método comparativo, que permitió establecer comparaciones entre el nivel de desarrollo de unas comunidades y otras.

- Elmétodo histórico lógico, proceso utilizado por los historiadores, consistente en ubicar el objeto de estudio en su contexto y evolución histórica.

\begin{abstract}
Al mismo tiempo cabe añadir la utilización de un método de trabajo basado en la reflexión participativa de los asistentes a las jornadas de capacitación llevadas a cabo en Jinotega sobre la base de las aportaciones de los líderes indígenas.
\end{abstract}

Los Materiales o Fuentes utilizadas fueron:

- Bibliografía especializada acerca de la identidad étnica y el contexto socio-histórico

- -Materiales primarios suministrados por los líderes de las comunidades acerca de la historia y el quehacer cotidiano de las mismas, principalmente en lo concerniente a especies animales y vegetales (medio ambiente) fuentes de vida material, relación de oficios y profesiones, la evolución de la población y los proyectos de desarrollo elaborados por hombres y mujeres de cada comunidad.

- También se utilizaron como elemento de análisis los materiales de trabajo que sirvieron de base a la capacitación-investigación realizada en Jinotega y fundamentalmente los resultados de la sistematización 
A través de la investigación se obtuvo una visión de la realidad de la Jinotega profunda y particularmente en lo que corresponde al movimiento indígena. Ello permitió aportar una visión menos urbana en lo que respecta al proyecto de investigación en Historia Regional y Local, especialmente en el apartado referido a la región Norte Central de Nicaragua. Como resultado práctico a través de la investigación emprendida con su vertiente de capacitación directa se contribuyó al empoderamiento del Pueblo Indígena de Jinotega que busca fortalecer y defender sus rasgos de identidad.

En el proceso de investigación llevado a cabo se demostró que a mayor conocimiento de la historia de la comunidad se logra el fortalecimiento de los rasgos de identidad de las comunidades y se establecen pautas para la consecución de proyectos autosostenidos que permiten combatir la pobreza Por otra parte, los conocimientos obtenidos por parte de los miembros de la comunidad y el proceso de reflexión llevado a cabo demuestra la importancia de la misma en el fortalecimiento de la organización y liderazgo popular.

Se optó por una metodología de trabajo reflexión-acción-participación basándose en el principio de que cada líder participante en los cursos de capacitación multiplicaría los conocimientos adquiridos en los mismos. Así se trataba de aplicar en cada comunidad las orientaciones emanadas en cada una de las sesiones de clase teniendo esto un efecto eminentemente práctico. Por ejemplo, tras los conocimientos adquiridos en el curso "Conociendo la comunidad", cada uno de los participantes, con el apoyo de algunos miembros de su comunidad respectiva elaboraron un 
pequeño ensayo sobre la historia de su entorno geográfico, económico, social y cultural. En la misma línea, a partir del curso sobre patrimonio cultural cada líder elaboró un inventario del patrimonio cultural tangible e intangible existente en su comunidad. Por otra parte, en cada una de las comarcas se formó el comité de emergencia encargado de organizar a la población en caso de sobrevenir un desastre de carácter natural. Por último, en la materia de formulación de proyectos cada participante con el apoyo de su comunidad elaboró un proyecto sostenible para ser impulsado. El resultado fue que se presentaron nueve proyectos. Después de una profunda reflexión por parte del equipo de docentes se seleccionó al que llevaba por título "Caficultura orgánica y reforestación en pro del medio ambiente" presentado por la comunidad de Paso Real y la cría de aves autóctonas, programa que se está llevando a cabo en la comunidad de “"El Yanke” El sostenimiento de este proyecto será responsabilidad de toda la comunidad.

\section{EL MARCO GEO-HISTÓRICO}

\section{Territorio y población}

La comunidad indígena de Jinotega abarca un total de 43.889 manzanas de extensión divididas en dos lotes: 36,000 en el lote número 1 y 7,000 en el lote número 2

El lote numero uno comprende la comarca de Apanás, Las Lomas, Tomatoya, Chagüite Grande, , El Mojón, Sisle, San Antonio de Sisle, Yanque, Paso Real, Mancotal, San Esteban y Los Robles. 
Y el lote numero dos incluye "Las praderas", "Los Limones, "La Reguera”, y "El Charcón"

La población indígena agrupa alrededor de 40,000 personas que habitan principalmente en dos municipios, el de Jinotega donde existen aproximadamente 35,000 indígenas, y el de Santa María de Pantasma, en el mismo departamento donde hay una cifra estimada de 4000 a 5000 indígenas ${ }^{3}$.

\section{La diferenciación del indígena de Jinotega}

Según los propios dirigentes del movimiento ellos diferencian al indígena por los apellidos mencionándose principalmente los siguientes: los Hernández, los Díaz, los Meléndez, los Castro, los Centeno. Se salen de la línea solamente cuando se casa una muchacha con un varón que no es indígena los hijos tienen otro apellido, pero siempre la sangre la transmiten por la línea materna. Sin embargo, es preciso reconocer que hay personas que llevan esos apellidos y no son indígenas. Al respecto el máximo dirigente del movimiento señala:

"Nosotros tenemos esto ya por naturaleza el conocimiento de la raza indígena. Es decir, como ya tengo 35 años de estar metido en las situaciones indígenas conozco todas las comarcas y familias indígenas y también a los que llegan por otro lado que pueden tener el mismo apellido pero que no son indígenas. Eso nos permite o nos facilita reconocer quien es indígena y quien no es indígena. Nosotros lo que

3 No obstante no existe un censo real, aunque en el año 2003 se levantó uno pero sin incluir al el indígena que no estaba en el territorio no entraban en el censo. 
hacemos es que nos reunimos los lideres que trabajamos en las comunidades y les damos instrucciones para que identifiquen a los indígenas entre las personas que llegan de otro lado."”

\section{ANTECEDENTES: EL ORDENAMIENTO JURÍDICO PARA LAS COMUNIDADES INDÍGENAS DEL PACÍFICO, CENTRO Y NORTE DEL PAÍS.}

La Conquista y la Colonia sometieron a los pueblos indígenas del Pacífico, Centro y Norte del país, quedando para fines del siglo XIX un número muy reducido de comunidades indígenas propietarias de tierras en esta parte del país. Cabe señalar que las tierras de esta parte del país están debidamente demarcadas así mismo inscritas a nombre de las comunidades indígenas respectivas en los competentes registros de la propiedad inmueble y mercantil de cada departamento donde se encuentran ubicadas estas comunidades 5 .

Las leyes integracionistas emitidas por el estado nacional fueron minando la supervivencia de estos pueblos hasta reducirlos en gran manera y cuya subsistencia ha sido posible debido a la propia persistencia indígena.

Estas leyes fueron emitidas a principios del siglo XX con la visión de que las comunidades indígenas eran dueñas de grandes extensiones de tierra y con el objeto de apoderarse de las mismas y convertir a los indígenas en campesinos que una vez desposeídos de sus tierras se convertirían en mano de obra barata y accesible. Por lo que las leyes de la época se enfocaron en regular las propiedades de las tierras de las comunidades indígenas, crear estatutos de las comunidades indígenas para crear y elegir las juntas de administración de los bienes de las comunidades indígenas.

$4 \quad$ Entrevista con miembros del movimiento indígena. Jinotega, julio de 2005.

5 González, Luis. Documentación básica sobre Derecho Indígena. (Material de capacitación). Jinotega, 2006. 
Resulta un problema recurrente que muchos de los conflictos históricos por la tierra tienen como común denominador la defensa de los derechos históricos de las comunidades indígenas, constituyendo este aspecto uno de los problemas heredados por el nuevo gobierno sandinista. En los últimos tiempos se han desatado las ambiciones de los geófagos sobre las tierras de las comunidades indígenas del Pacífico y Centro de Nicaragua.

Las leyes actuales de la propiedad tratan a los miembros de las comunidades indígenas exclusivamente como comuneros, poseedores de tierras y le negaron a las comunidades sus derechos culturales y políticos como las asociaciones naturales que comparten, entre otros elementos de vida comunitaria la tenencia colectiva de la tierra, los lazos étnicos, sociales y la cosmovisión e identidad.

La injerencia estatal promovida por estas leyes en la organización de las juntas comunitarias o directivas minó la cohesión cultural y organización de las comunidades indígenas debido a la intervención estatal en la vida interna de los pueblos. Estas leyes a pesar de los aciertos y desaciertos que contengan continúan en vigencia y son parte del ordenamiento jurídico nacional y se deben respetar, lo que compete a los pueblos originarios es luchar para que sean reformadas estas leyes y se incorporen los elementos políticos y culturales que se les niegan en las actuales leyes.

Es importante destacar que el régimen especial autónomo de rango constitucional creado en 1987 para los pueblos indígenas de la Costa Atlántica de Nicaragua tiene otras características entre las que encontramos el respeto a las costumbres y tradiciones dentro de las comunidades a elegir libremente a sus líderes 6 .

\section{La organización indígena}

$6 \quad$ Ibid. 
La estructura de la familia indígena es patriarcal aunque el fuerte proceso de inmigración y colonización ha afectado a la misma. En cuanto al papel que desempeña la mujer hay opiniones encontradas al respecto. No obstante la mayoría de los entrevistados, especialmente líderes indígenas consultados, señalan que hasta ahora se le está dando importancia a la mujer. Anteriormente solo los hombres participaban en las votaciones para elegir junta directiva y, consecuentemente con ello, los cargos recaían únicamente en los indígenas de sexo masculino. En ese sentido, Juan González, cacique mayor, señala:

“Desde 1996 en que asumo el puesto de cacique del pueblo indígena se les abrió las puertas a las mujeres para que ellas entraran con su misma participación como con su mismo derecho, con su misma obligación de defender sus derechos de pelear por sus derechos"7.

La autoridad tradicional era y es ejercida a través del cacique, la máxima autoridad de los pueblos y bajo la orden del cacique, el pueblo por que el cacique era guerrero y político, tenía una función primordial, aunque ese peso se ha venido perdiendo, sobre todo por la injerencia del poder de las instituciones modernas.

En cuanto a la juventud indígena, hasta el momento no hay una organización pero recientemente se han venido formando comisiones de deportes, de salud, de agricultores, y dejamos ahí organizado. No le dimos seguimiento por causa pero siempre de diversión pero pensamos que vamos a hacer ese nueva actividad con los que están preparándose ahorita nos sirven de apoyo 7 Entrevista con Juan González, cacique del Pueblo Indígena de Jinotega, agosto de 2005 
para eso que la comunidad tenga su identidad sin salirse de lo que le corresponde a ellos,

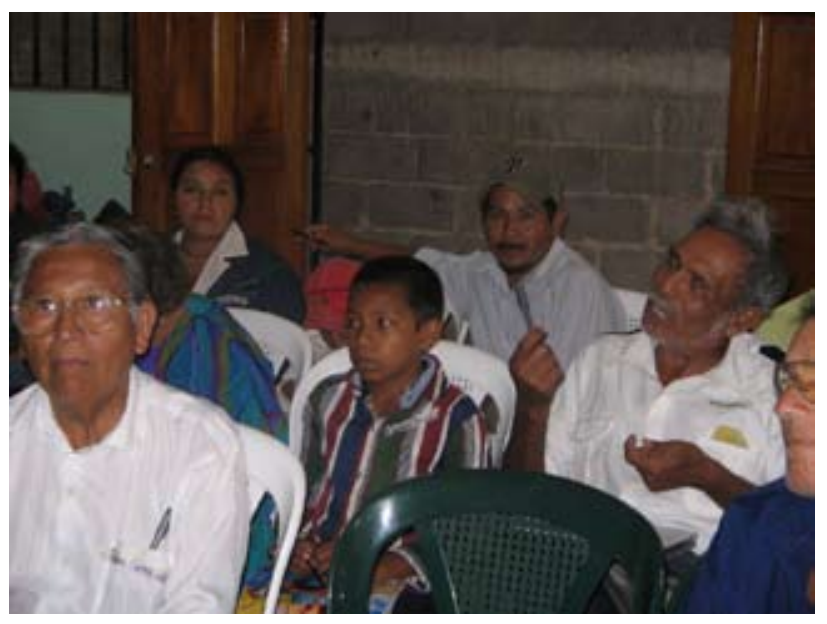

\section{El Consejo de Ancianos}

Durante la Junta Directiva pasada, estaba formado por dos miembros por cada comarca, eran 38 miembros y como no se les dio una capacitación formal, la junta directiva comenzaron a desintegrarse, a quitar unos miembros y poner a otros, pero realmente eso lo hicieron por falta de conocimiento, porque el Consejo es vitalicio, no se puede cambiar y los miembros permanecen en el cargo hasta su fallecimiento. Juan González añade:

“Actualmente les hice un llamado al consejo para que entráramos a reflexión para que nos preparáramos y actuáramos de la manera correcta y los miembros del consejo algunos vinieron otro no, y no hicimos lo que pretendíamos hacer lograr, establecer una relación con los que andan en contra buscar como unirnos en una sola voz y hacerlos reflexionar que el pueblo no puede estar dividido sino que marchemos hacia lo justo y buscar una victoria y no estar de esa manera en división sin embargo hasta el momento no he hecho ninguna reunión. No esta programada 
alguna actividad, esperando esta fase del estudio que se esta haciendo ahorita con la universidad, para llevar a cabo una asamblea general donde salgan propuestas del pueblo y que sean benéficas para el desarrollo del pueblo indígena"”,

\section{Poder indígena-poder local}

¿Que relación tradicional de hace tiempo ha venido teniendo la comunidad indígena con los alcaldes, y con las municipalidades cual ha sido la relación?

La ley dice que los alcaldes deben de dar las certificaciones de las tomas de posesiones de la directivas, firmar las boletas de votación y retirar el certificado, ninguna función más tiene la alcaldía municipal. Sin embargo, ellos apoyan a la directiva que ellos quieren, que las manejan a su voluntad, sobre todo por el interés de recaudar los impuestos. La ley dice que ningún indígena tiene deber de pagar ningún impuesto, todo aquel que tiene menos de cincuenta manzanas debe pagar impuestos en la alcaldía municipal, pero las alcaldías pretenden que todos deben de pagar el impuesto y eso ha sido una lucha permanente.

También cabe añadir que existe en la actualidad un diferendo entre el Movimiento Indígena y la directiva desde 1996, en que estaba de presidente Federico López Granados, quien llevó el titulo a la Universidad Centroamericana (UCA) administrada por los jesuitas para que fuera restaurado pero esa restauración no se ha visto hasta el momento. Según los miembros del movimiento "han estado engañando al pueblo indígena diciendo que tienen el titulo, que lo restauraron. Pero no está aquí, está, en la UCA bajo una escritura pública aunque se están haciendo gestiones para 
recuperar ese título pero el rector nos dijo que solamente las personas que habían firmado las escrituras es que podían entregarles el titulo"8.

Las autoridades civiles son: un alcalde auxiliar, a quien el poder se lo da el alcalde de la cabecera departamental, quien recoge las necesidades de dicha comunidad a través de un comité de distrito y esta las transmite al Alcalde del Departamento, se cuenta con vigilante de la Comunidad Indígena.

También existen traslapadas a la propia organización indígena comités de padres de familia que son electos en la asamblea de la comunidad. Otras autoridades civiles son el comité de agua potable, "tres" organizaciones que trabajan con la comunidad como "Aldea Global" e INTA (Instituto Nicaragüense de Tecnología Agropecuaria), que son gubernamentales y trabajan en apoyo a la caficultura. Las organizaciones políticas que tiene presencia en la comunidad son el Frente Sandinista de Liberación Nacional (FSLN) y el Partido Liberal Constitucionalista (PLC).

\section{.El régimen político y los derechos indígenas}

¿La revolución sandinista cambió algo para el indígena?.

Realmente sí. Muchos indígenas que no tenían tierra donde trabajar fueron favorecidos, pero también las directivas que estaban en esa época no hacían lo correcto, no se acercaban a tener una relación con los que estaban en el poder, hubo una época en que estuvo inactiva la situación del pueblo indígena, por un período Los que estaban en el poder de la comunidad eran liberales 8 Entrevista con dirigentes del movimiento indígena de Jinotega. Jinotega, julio de 2005 
o conservadores y como había choques con el FSLN no actuaban beligerantemente, afectando a la identidad comunitaria. No obstante, en el tiempo de la revolución el indígena recuperó sus tierras.

La situación del movimiento indígena fue cambiando a partir de los años noventa. pero viendo la situaciones que se dan, las injusticias que se daban se consideró pertinente formar un movimiento indígena autónomo que recuperara sus poderes tradicionales. Juan González señala al respecto:

“Formé el Consejo de Ancianos en 1996 y comenzamos a trabajar de una manera bien ordenada, pero siempre la cizaña del enemigo es astuta y comenzaron a que hubiera choque entre consejo y la junta directiva y desde ahí ha venido un divisionismo que hasta estos momentos ha habido ese choque entre nosotros mismos, anteriormente le decía la falta de conocimiento, por no conocer las leyes, los derechos, todas esas cosas han venido perturbando y por esa razón yo digo que ahora que estamos conectados con la universidad, nos va hacer despertar, nos va hacer que tengamos un cambio radical. ${ }^{9}$ "

Uno de los problemas enfrentados en los últimos años -añade González- fue el intento de privatización del lago de Apanás, este hay un problema de privatización. "la alcaldía quería tomar el lago como un lugar turístico y ellos siempre han estados propuesto a llevar a cabo esa relación con la junta directiva de que eso pase a manos de la alcaldía. Incluso ahorita parece que con el arriendo que había llevado que tenia que pagar el gobierno, la alcaldía municipales dijeron 9 Entrevista con Juan González, cacique del pueblo indígena de Jinotega, agosto de 2006 
que iban a recibir el 5\% de ese pago y las comunidades indígenas, solo iban a recibir el 1\%"

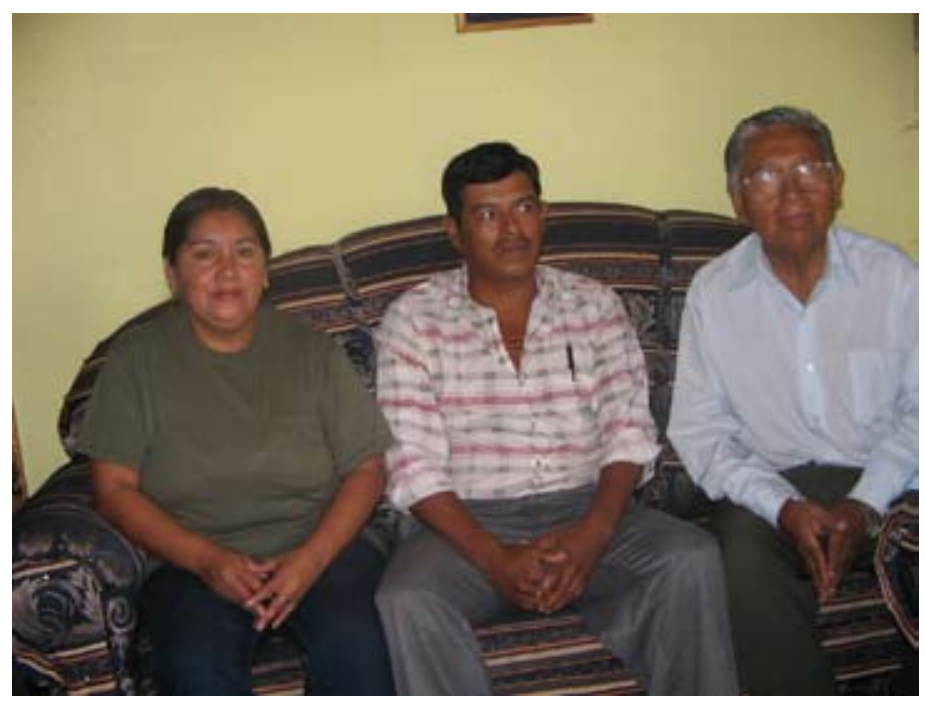

El indígena ha tenido acceso a la tierra pero ha ido perdiendo su patrimonio; han vendido sus tierras y emigrado hacia la ciudad o fuera del país. En múltiples ocasiones no ha querido mantener su patrimonio, lo ha abandonado por diferentes causas.

\section{La identidad cultural: música, tradiciones y leyendas.}

Los principales instrumentos musicales que se utilizan en las comunidades indígenas de Jinotega son el acordeón, la guitarra y la bandolina, este instrumento lo hacía de concha de cuzuco (armadillo), sus cuerdas son de nylon, estos instrumentos se tocaban antes de 1975. En estas comunidades existen grupos de música tradicional que desempeñan en distintos géneros tales como rancheros, polkas, mazurcas y el popular jamaqueo. Cada una de las comunidades tiene su propio grupo musical, compuesto por dos cuartetos y tríos. Estos grupos componen sus propias 
canciones, después de las tradicionales ellos tocan la guitarra, guitarrón, virguela, requinto y acordeón.

Se hace notar la influencia de la inmigración centroeuropea en la música jinotegana. Tocan en fiestas, cumpleaños, serenatas, celebraciones de la palabra de Dios dominicales o semanales, o en encuentros artísticos. Actualmente se están rescatando los valores culturales y artísticos, ya que existe la presencia de Jinotegarte ${ }^{10}$, una organización que está luchando por el rescate de la música vernácula inédita.

En cuanto a las costumbres religiosas la comunidad mantiene las tradiciones católicas. Entre ellas, los novenarios, donde participan de 60 a 70 personas por día en cada comunidad. También, es popular el rezo del rosario por sectores, casa a casa, de las 4pm a 6pm con cánticos. También se da reconocimiento según explica uan dirigente indígena a la herencia de la tierra de "nuestros padres, los bienes inmuebles, animales, escrituras que nos otorgan de uso y goce por ser herederos indígenas".

Actividades religiosas. Las fiestas patronales son en honor el Señor de Esquipulas, se celebra los 15 de enero, con vigilia toda la noche. Al siguiente día se celebra la misa solemne. También se celebra la Purísima, los 7 de diciembre, el Niño Dios, el 24 de diciembre y también la Misión de la Virgen de Fátima.

10 Institución jinotegana dedicada al rescate y promoción de las tradiciones culturales y artísiticas. 
Resultados obtenidos en el proceso de investigación.

- Fortalecimiento del liderazgo interno de las respectivas comunidades que conforman el Pueblo Indígena de Jinotega.

- Elaboración de nueve proyectos comunitarios que constituyen un banco de necesidades de la población más empobrecida dentro de las áreas de impacto del programa de capacitación.

- Obtención de una base de datos sobre recursos de flora, fauna y de aspectos relativos al patrimonio cultural tangible e intangible en cada una de las comunidades.

- Formación de los comités de emergencia frente a desastres naturales en cada uno de los lugares de procedencia de los participantes en el programa de capacitación.

- Detección de sitios eco-turísticos potenciales con vistas a ser explotados bajo un criterio de sostenibilidad y respeto al medio ambiente.

\section{Bibliografía:}

VV.AA. Revista de Historia. No. 14. IHNCA, UCA, $1992 .$.

Téllez, Dora María. ¡Muera la Gobierna!. Colonización en Matagalpa y Jinotega (1820-1890). Nicaragua, URACCAN, 1999. 
Indexaciones: Repositorio de Revistas UCR, DIALNET, Latindex, REDALYC Directorio y recolector de recursos digitales del Ministerio de Cultura de España, Directory of Open Access Journals. Diálogos Revista Electrónica de Historia ISSN 1409-469X. Número especial 2008. Dirección web: http://historia.fcs.ucr.ac.cr/dialogos.htm

Romero, Jilma [et al.]. Región Norte Central de Nicaragua. Matagalpa y Jinotega a través de su historia. UNAN-Managua, Nicaragua, 2005.

Lobato Blanco, Luis A. [Ed.]. “Abriendo surcos”. Memoria de las actividades de capacitación llevadas a cabo en el municipio de Jinotega. Edit. UNAN-Managua, diciembre de 2005.

Lobato Blanco, L., Balladares, S., Gómez, J. "El Fortalecimiento de la identidad local para el desarrollo sostenible. La experiencia en la formación del liderazgo en los pueblos indígenas de Jinotega y Veracruz del Zapotal (Rivas)", En Memoria del XIII Congreso Científico de la UNANManagua. Editada por la Facultad de Ciencias de la Educación y Humanidades. Departamento de Historia. 